\title{
Psychological Wellbeing, Perceived Emotional Intelligenceand Locus of Control Predicting Adolescents' Sexual Health Risk Behaviour: Lesson from Nigeria
}

\author{
Ogunsanwo, MojisolaAbiodun, Ayodele, KolawoleOlanrewaju PhD \\ ${ }^{1}$ Institute of EducationOlabisiOnabanjo UniversityAgo-Iwoye, Ogun State, Nigeria \\ ${ }^{2}$ Office of Institutional Effectiveness (OIE)Babcock University Ilishan, Ogun State, Nigeria
}

\begin{abstract}
This study investigated the relationships of psychological wellbeing, emotional intelligence, and locus of control to the prediction of sexual health behaviour among Nigerian adolescents. It further established the influence of gender, parents' socio-economic factors and family structure on adolescents' sexual health behaviour. Participants were 4,563adolescentsrandomly selected from twenty-four (24) secondary schools in 12 local government areas out of 20 in Ogun State, Nigeria.Measures of biographical data, psychological wellbeing, emotional intelligence, locus of control and sexual behaviourscales were administered on the sample. Correlation matrixand hierarchical multiple regression analysis was used to analyse the data collected. Results showed that all the demographic factors $\left(\Delta R 2=.04, d f_{(3,4559)}=3.817, p<.05\right)$ and psychological wellbeing $(\Delta R 2$ $\left.=.267, \beta=.55, d f_{(4,4558)}=7.123, p<.05\right)$, emotional intelligence $\left(\Delta R 2=.176, \beta=.37, d f_{(5,4557)}=4.827, p<\right.$ $.05)$, locus of control $\left(\Delta R 2=.176, \beta=.37, d f_{(6,4557)}=9.229, p<.05\right)$ significantly predicted adolescents' sexual health behaviour. Findings suggest the need for the homes to play a significant role in the proper psychosocial development of the child, and must not shy away from educating the child about sexuality (reproductive healthy knowledge).
\end{abstract}

Keywords: Psychological wellbeing, emotional intelligence, locus of control, sexual health behaviour

\section{Introduction}

Since the time Nigeria move away from agrarian community into a civilized and technological driven community, most of our valued cultures have been lost. One of such is the sexual revolution that has made most of our adolescents sexually active and cohabits before marriage. Ayodele (2010) noted that more than 58\% of our adolescents are sexually active right from age 16 and entering adulthood sexually experienced. Our homes and schools have offered multiple opportunities for the exploration of sexual relationships, which has lead to sudden and quick sexual decision. Allen, Husser, Stone, \&Jordal, (2008) confirmed that sexual decision making among students in high schools, colleges, and higher institutions is integral to their experiences during emerging adulthood.

Studies in Nigeria have shown that sexual activities have taken a high dimension among unmarried youths with higher incidences being recorded among urban girls and boys (Akindele-Oscar \&Ayodele, 2004; Makinde, 2004; Ogunsanya, 2007). It is so glaring, therefore, that Nigerian youths are becoming predominantly pre-marital in their sexual activities. Despite religious, cultural and legal sanctions against premarital sex in many parts of the world, dramatic change in sexual attitudes and interactions have become a common and widely accepted part of romantic relationships (Baron \&Bryne, 1997 cited in Akindele-Oscar \&Ayodele, 2004).

Ogunsanya (2007) in her study of adolescents' perception of sex symbol, values, risks and misconceptions reported that $77 \%$ of girls from co-educational school see abstinences as a forced value and that having sex early makes them discover their identity. $37 \%$ of the boys on the other hand perceived sex as love while $40 \%$ of boys believe that a relationship without sex cannot last. Akindele-Oscar \&Ayodele (2004) also established that adolescents' lack of knowledge of reproductive health has a significant relationship with their permissive sexual expressions. This tend to show, that engaging in casual sex was not necessarily always a deliberate choice, often times it was due to lack of adequate sexual health knowledge or complete ignorance on the subject matter.

It is believe that individual with adequate and sufficient knowledge on reproductive health matters and how to manage his or her life no matter the circumstances that surrounds him or her would be able to know how to control self or play safe and not necessarily engage in complete abstinence from sex. What then is sexual health?

Sexual health as defined by the World Health Organization (WHO) is seen as a state of physical,emotional, mental and social well-being. In relation to sexuality it is notmerely the absence of disease, dysfunction, or infirmity butrequires a positive and respectful approach to sexuality and sexualrelationships, as 
well as the possibility of having pleasurable and safe sexualexperiences, free of coercion, discrimination, and violence (WHO, 2012). However, some scholars and researcher also view sexual health from medical perspective of which they believe it involve prevention of STIs and unintended pregnancy among sexually active individuals, be it adolescents or adults (Ayodele, 2010; Kane \&Wellings, 1999; Krivohlavy, 2003; Ogunleye\&Oke, 2012). It could be deduced from the views of the researchers and scholars cited above that sexual health goes beyond the occurrence or prevention of sexually transmitted infections (STIs) and unintended pregnancies but also about enjoyment and pleasure. This is supported by the assertions of Coleman et al., (2007) that sexual health is also about enjoyment and pleasure.

Psychological well-being is a multi-dimensional concept, which describes positive and negative emotions, worries and stress, life-satisfaction and optimism. Self-esteem, well-being, religiousness and personal values are some of the psychological factors shown to have been associated with sexual behaviour (Mann et al., 2004). In a meta-analysis study byOndrej (2012) revealed that some studies which explored the role of selfesteem on sexual behaviour showed that $60 \%$ of the studies found no associations between self-esteem on sexual behaviour while an expected protective role of self-esteem was not revealed. In spite of this, self-esteem has been reported to play an important role in sexual health behaviour especially in the realm of its risk-taking behaviour among adolescents and young adults. For instance, the studies of Davies et al., (2003), and Preston et al., (2004) revealed an association between low self-esteem and sexual risk behaviour, as well as the consequences of sexual risk behaviour such as STI and unwanted pregnancies. In another study, it was reported that low self-esteem (poor psychological wellbeing) predicted both early onset of sexual activity and unprotected sex on a large cross-sectional sample of adolescents while high self-esteem (good psychological wellbeing)is positively associated with less sexual risk behaviour (Magnani, 2001; Ogunleye\&Oke, 2012).

One of the major variables that in recent time has attracted a lot of significance in the academic literature emotional intelligence (EI) or perceived emotional intelligence (Fernández-Berrocal\&Extremera 2008; Mabekoje\&Ogunyemi, 2003; Ogunyemi, 2008; Shulman \&Hemenover 2006). Emotional intelligence describes the ability, capacity, or skill to perceive, assess, and manage the emotions of oneself, those of others and of groups (Salovey\& Mayer, 1990). The construct has also been described as the ability to recognize the meanings of emotions, relationships, to reason and solve problems (Mayer, Caruso, \&Salovey, 2000; Mayer, Salovey\& Caruso, 1999; 2002). EI have been found to be associated with outcomes such as life satisfaction and social network size and quality (Ciarrochi, Chan, \&Bajgar, 2001; Fernandez-Berrocal\& Ruiz, 2008; Palmer, Donaldson, \&Stough, 2002; Saklofske, Austin, \&Minski, 2003). Emotional intelligence has furthermore been shown by research to predict positive relations with active coping and positive rethinking (Gohm\&Clore 2002), higher emotional adjustment (Berking et al. 2008), and negative relations with passive coping or intrusive thoughts (Ramos et al. 2007; Salovey et al. 2002), as well as emotional clarity and repair Salguero and Iruarrizaga 2006; Salovey et al. 1995; Thayer et al. (2003).

Locus of control (LOC) has been report over the years as a major construct in individual's life that play a major role in many aspects of human behavior such as self-control, socially adjustment, independence, expectancy, achievement motivation and success-orientation. It is seen as the degree to which individual believes that their behaviours are controlled by external or internal factors. The findings of Carrim, Basson, \& Coetzee, (2006), Gizir\&Aydin (2009), Tella, Tella, \&Adeyinka, (2008) have shown that individuals with a high external locus of control believe that fate or chance determine the outcome of events while individuals with a high internal locus of control believe that the results of events are caused by their own actions and behaviour (Boone, van Olffen\& van Witteloostuijn, 2005; Carrim, Basson, \& Coetzee, 2006). Therefore, LOC has been viewed by Lee-Kelley (2006) as a dimension with two opposing differentiates. These dimensions according to Carrim, Basson, \& Coetzee (2006) reflect the extent to which individuals believe that what happens to them is within their control or beyond it.

It is the believe that the inclusion of psychological wellbeing, perceived emotional intelligence and locus of control in this study would be of help in assessing the relationship among these variables in predicting adolescents' sexual health behaviour and how better to help them live a meaningful and healthy life.

\section{The Problem}

Adolescents' sexual health behaviour has been the focus of several studies comparing male and female (Lambert, Kahn, \& Apple, 2003; Paul \& Hayes, 2002), while less attention has addressed the influence of psychological wellbeing, emotional intelligence, and locus of control on sexual health behaviors specifically among adolescents in Nigeria. What most studies have focused on has been sexual risk behaviour among the youths which has manifest itself with other behaviour such sex abuse, sex offences, sexual misconduct, sexual immorality, sexual promiscuity, sexual maladjustment, delinquency and substance use, without really looking at some predisposing factors that made them prone to such sexual risk behaviour (Adedipe, 2000; Ndu, 2000, Nnachi, 2003; Odoemelam, 1996; Patrick \&Maggs, 2009; Cavazos-Rehg et al., 2010). This study therefore, tends to fill such gap in Nigeria. More research is also needed to examine the role of these variables in the 
fostering positive sexual health behaviour among our adolescents. This study therefore examined the role of perceived emotional intelligence,psychological wellbeing and locus of control in the prediction of adolescents' sexual health risk behaviour.

\section{Research Hypotheses}

The following hypotheses were formulated and tested at 0.05 significant level:

1. Gender, parents' socio-economic background, and family structure will significantly predict adolescents' sexual health behaviour.

2. Psychological wellbeing will significantly predict adolescents' sexual healthbehaviour.

3. Perceived emotional intelligence will significantly predict adolescents' sexual healthbehaviour.

4. Locus of control will significantly predict adolescents' sexual healthbehaviour.

\section{Methodology}

The study adopted a survey research design using an ex-post facto type. This design usually collects data after the event or phenomenon under investigation has taken place. In the course of this study, the researchers had no control over the variables of interest and could not manipulate them.

Sample and Sampling Procedure: Participants for this study were selected from Ogun State Nigeria for a period of five weeks and four days. The State was stratified into four major educational divisions namely: Remo, Ijebu, Yewa and Egba (RIYE). There are twenty Local Government Areas in the four Educational divisions in Ogun State. From each of the division, three LGAs were randomly selected. Furthermore, two senior secondary schools were selected through random sampling technique from each of the twelve selected local government areas making a total of twenty-four (24) participating schools. Therefore, the researchers were able to cover 12 out of 20 Local Government Councils $(60 \%)$ within the four educational divisions that made up the sample population. In all, 4,800 questionnaires were used for data collection, Out of these, 4,563 questionnaires were retrieved for data analysis. This gave a return rate of $95.1 \%$.

Measures: Four validated instruments were used for data collection apart from the personal attributes scale as shown hereunder. Personal attributesin the study were gender (male and female), school location (urban and rural), and parents' socio-economic status (high, average, and low).

1. Well-Being Manifestation Measure Scale (WBMMS): WBMMS was used to measure psychologicalwellbeing. This scale was developed by Masse, Poulin, Dassa, Lambert, Belair, \&Battaglini (1998) and consists of 25-items with subscales. The six subscales of the WBMMS are: control of self andevents, happiness, social involvement, self-esteem,mental balance, and sociability.An overall Crobach'salpha of 0.93 was reported for the scale and arange of 0.71 to 0.85 on the subscales (Masse, Poulin, Dassa, Lambert, Belair, \&Battaglini, 1998).

2. Perceived emotional intelligence (PEI): The Trait Meta-Mood Scale (TMMS) developed by Salovey et al. (1995) was used to assess PEI. The scale is a five-point Likert scale designed to assess how people reflect upon their moods and manage their emotions and feelings. Examples of the items of the scale are (1) "I pay a lot of attention to how I feel", "I am usually very clear about my feelings", "No matter how badly I feel, I try to think about pleasant things". The scale was found to be suitable for Nigerian samples (Mabekoje, 2012). TMMS has shown adequate psychometric properties in adolescent population with a Cronbach's alpha of .81 in this study.

3. Locus of Control (LOC): Child Nowicki-Strickland Internal-External control scale (CNSIE) developed by Nowicki\& Strickland (1974) and used by Farbstein (2011) was used to measure locus of control. It is a 40 item scale measured on 2 continuums as either yes or no. An example of sample item is, "Do you feel that when you do something wrong there's very little you can do to make it right?" The scale has reliability coefficient of .83. In this study, the internal consistency reliability of the LOC by Cronbach's alpha is .79. The scale was found to be suitable for Nigerian samples.

4. Adolescents' Sexual Behaviour Scale(ASBS)-Adolescents Sexual Behaviour was assessed using Adolescents Sexual Behaviour Inventory (ASEBI) developed by Akindele-Oscar \&Ayodele (2004). The 30-item questionnaire consisted of 3 subscales on sexual reproductive knowledge, sexual attachment behaviour and sexual initiating/experimenting behaviour each with 10 items constructed in five-point likert format measured along very much like me (5), much like me (4), like me (3), unlike me (2), and very much unlike me (1). Sample items include for sexual reproductive knowledge: "I see no reason why I should be worried about the possibility of having AIDS"; for sexual attachment behaviour: "I always go out with the opposite sex"; and for sexual initiating/experimenting behaviour: "I easily give in to sex when caressed".

Control Variables: Two control variables included in this study were gender, parents' socio-economic status, and family structure. These variables were measured as follows: 
Gender: Respondents were asked to report their gender. In the data compilation, gender was coded as follows: male $=1$ and female $=0$.

Parents' socio-economic status (PSES): The respondents were requested to report their parents' socioeconomic scale on a five item scale. PSES was coded low =1,2= average, and $3=$ high.

Family Structure:The respondents were requested to report their family structure. One (1) was coded for single parenting, 2 for double parenting, and 3 for living with foster parents/guardian/significant others.

Data Analysis: Data collected were analyzed using correlation matrix and hierarchical multiple analysis in order to establish the relationship of the independent variables with the dependent

regression

variables.

\section{Results}

Results on table 1 show significant positive correlations between adolescents' sexualbehavior and happiness $(\mathrm{r}=.27, \mathrm{p}<.05)$, social involvement $(\mathrm{r}=.20, \mathrm{p}<.05)$, sociability $(\mathrm{r}=.30, \mathrm{p}<.05)$, and locus of control $(\mathrm{r}=.35, \mathrm{p}<.05)$, while negative correlation was found between sexual behaviour and control of self and events $(r=.-22, p<.05), p>.05)$, self-esteem $(r=.20, p<.05)$, mental balance $(r=-.19, p>.05)$ and emotional intelligence $(\mathrm{r}=-.21, \mathrm{p}>.05)$.

Table 1: Correlation matrix of psychological wellbeing components across other variables in the

\begin{tabular}{|c|c|c|c|c|c|c|c|c|c|c|}
\hline $\mathrm{SN}$ & & 1 & 2 & 3 & 4 & 5 & 6 & 7 & 8 & 9 \\
\hline 1 & Control of self and events & - & & & & & & & & \\
\hline 2 & Happiness & $.35 * *$ & - & & & & & & & \\
\hline 3 & Social Involvement & $.28 * *$ & $.40 * *$ & - & & & & & & \\
\hline 4 & Self-esteem & $.30 * *$ & $.31 * *$ & $.35 * *$ & - & & & & & \\
\hline 5 & Mental Balance & $.33 * *$ & $.37 * *$ & $.35^{* *}$ & $.38 * *$ & - & & & & \\
\hline 6 & Sociability & $.30 * *$ & $.29 * *$ & $.40 * *$ & $.27 * *$ & $.32 * *$ & - & & & \\
\hline 7 & Emotional Intelligence & $.38 * *$ & $.42 * *$ & $.33 * *$ & $.30 * *$ & $.29 * *$ & $.35^{* *}$ & - & & \\
\hline 8 & Locus of Control & $.27 *$ & $.25 * *$ & $.30 * *$ & $.22 * *$ & $.17 * *$ & $.23 * *$ & $.18 * *$ & - & \\
\hline 9 & Sexual Behaviour &.$-22 * *$ & $.27 * *$ & $.29 * *$ &.$-20 * *$ & $-.19 * *$ & $.30 * *$ & $-.21 * *$ & $.35^{* *}$ & - \\
\hline
\end{tabular}

$* \mathrm{p}<.01, * * \mathrm{p}<.05$

Table 2 below showed a five-step performed hierarchical regression testing the predictability of adolescents' sexual behavior based demographics in step 1, psychological wellbeing in step 2, emotional intelligence in step 3, and locus of control in step 4.The results in step 1 indicated that demographic factors (gender, parents' socio-economic status, and school location) significantly predicted adolescents' sexual behaviour $\left(\Delta \mathrm{R} 2=.04, \mathrm{df}_{(3,4559)}=3.817, \mathrm{p}<.05\right)$. Gender, family structure and parents' socio-economic status made significant separate contributions to the prediction of adolescents' sexual behaviour. Male and female adolescents were significantly different in their sexual behaviour $(\beta=.21)$. Adolescents from double home (where the two parents are present) differ in their sexual behaviour compared to those from single home $(\beta=$ .13). Also, adolescents from high parental socio-economic status differ from their counterpart from low parental socio-economic status $(\beta=.17)$. Therefore, demographic factors were found to influence adolescents' sexual behaviour.

The influence of the psychological wellbeing on adolescents' sexual behaviour as shown in step 2 revealed a significant influence $\left(\Delta \mathrm{R} 2=.267, \beta=.55, \mathrm{df}_{(4,4558)}=7.123, \mathrm{p}<.05\right)$, thus confirming the hypothesis which stated that psychological wellbeing will significantly influence adolescents' sexual behaviour. It could be deduced from the outcome of hypothesis two that adolescents with positive scores on the psychological wellbeing scale also had positive scores of sexual behaviour score. In step 3, the result of the influence of emotional intelligence on adolescents' sexual behaviour was significantly predicted $(\Delta \mathrm{R} 2=.176, \beta=.37$, $\left.\mathrm{df}_{(5,4557)}=4.827, \mathrm{p}<.05\right)$. Hypothesis four is therefore sustained as theadolescents higher in emotional intelligence also had higher scores in positive sexual behavioural scale. When locus of control was added in step 4 significant prediction was found on positive sexual behavioural $\left(\Delta \mathrm{R} 2=.176, \beta=.37, \mathrm{df}_{(6,4557)}=9.229, \mathrm{p}<\right.$ $.05)$. This is an indication that locus of controlplay significant role in predicting adolescents' positive sexual behaviour. 
Table 2: Hierarchical multiple regression analysis of Organization-based self-esteem, Spirituality at work Organizational Citizenship Behaviour, and Demographic factor on Organizational commitment

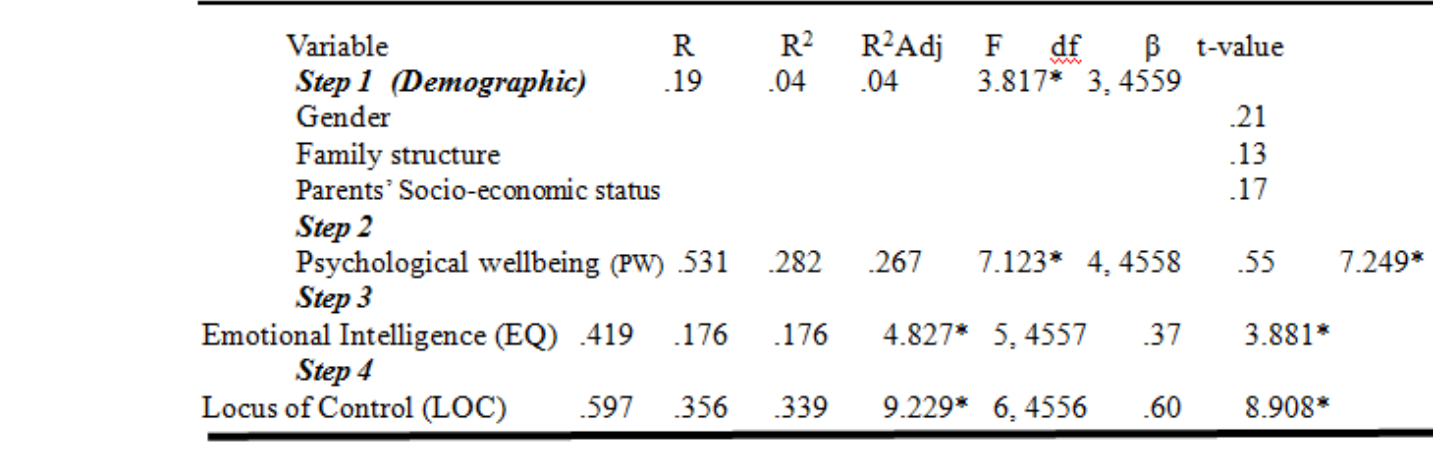

Note: $N=4563, * P<.05(2-t a i l e d)$

\section{Discussion of Findings}

The findings of this study showed that adolescents' sexual health behaviour was positively related tothree out of six of psychological wellbeing factors (happiness, social involvement, and sociability) and locus of control except for control of self and events, self-esteem,mental balance and emotional intelligence.The empirical result shows that adolescents' sexual health behaviour to some degree will be significantly affected by psychological wellbeing factors, locus of control and emotional intelligence. The implication is that in an African country like Nigeria, with a tight mindset on less discussion on adolescents' sexuality at home and tight social framework may pose a serious challenge on adolescents' sexual health behaviour, in spite of various orientations and campaigns by Government and Non-governmental agencies. Therefore, various psychosocial factors should be explored in order to identify the ideal adolescents' sexual behaviour with a major focus on the home which is the first socialization unit of the child. These home elements among others are parenting skills, family functioning, and psychological well-being of the individuals in the family, parenting style, the quality of life, marriage satisfaction, and relationships among family members. These elements influence the foundation of other behaviours in the long run.This findings therefore lend credence to past findings which established that sexual decision making among students in high schools, colleges, and higher institutions is integral to their experiences during emerging adulthood(Allen, Husser, Stone, \&Jordal, (2008), and that despite religious, cultural and legal sanctions against premarital sex in many parts of the world, dramatic change in sexual attitudes and interactions have become a common and widely accepted part of romantic relationships (Baron \&Bryne, 1997 cited in Akindele-Oscar \&Ayodele, 2004).

Gender, parents' socio-economic background, and family structure were found by the outcome of this finding to significantly predict adolescents' sexual health behaviour. It could then be said that socio-personal variables to degree may be relevant factors regarding adolescents' sexual health behaviourespecially sexual risk behaviours. This result corroborates the findings of De Graaf et al., (2010), Potard et al., (2008), and Sieverding et al., (2005) that heterogeneous psychological and social factors such as family structure, parenting practices, and peers were frequently found as relevant factors regarding sexual risk behavioursamong adolescents. While it contradicts the finding of Langille (2003) who found no significant associations between the family arrangement and sexual behaviours, except between living with both parents and contraception use.

The finding that psychological wellbeing significantly predicted adolescents' sexual health behaviour support the findings of other researchers who reported that psychological wellbeingdescribes positive and negative emotions have been shown to be associated with sexual behaviour (Mann et al., 2004). Also, this study lend credence to findings of Magnani, (2001) and Ogunleye\&Oke, (2012) that poor psychological wellbeing (low self-esteem) predicted both early onset of sexual activity and unprotected sex on a large cross-sectional sample of adolescents while good psychological wellbeing (high self-esteem) is positively associated with less sexual risk behaviour.It could be explainedtherefore that individual with good psychological wellbeingpossession could display and live positive sexual health behaviour without necessarily abstaining from sex.

That Perceived emotional intelligence significantly predicted adolescents' sexual health behaviour is consistent with the findings of previous researchers (Fernandez-Berrocal\& Ruiz, 2008; Palmer, Donaldson, \&Stough, 2002; Saklofske, Austin, \&Minski, 2003) who found significant relationship between emotional intelligence and behavioural outcomes such as life satisfaction and social network size and quality. An explanation for this finding is that adolescenthigh emotional intelligence is likely to perceive, express and regulate emotions which could affect their attitude toward sexual relationship in a positive manner and will be able to cope with intrusive thoughts. 


\section{Conclusion and Limitation of the Study}

This study has established both divergent and convergent correlation between psychological wellbeing factors, perceived emotional intelligence, locus of control, and adolescents' sexual health behaviour.The accurate predictability of psychological wellbeing factors on perceived emotional intelligence, locus of control, and adolescents' sexual health behaviourhas important implications for adolescents' psychosocial development, training and education.

The results of the study revealed that gender, parents' socio-economic background, and family structure significantly correlated with adolescents' sexual health behaviour. This means that some demographic factors can make adolescents to be prone to unhealthy sexual behaviour. For instance,living with two parents can further protect adolescents from engaging in sexual risk behaviour due to parental monitoring and support, connectedness, communication between parents and child and quality of relationship.

It is therefore recommended that the home which is the first socialization unit and first contact of the child needs to play a significant role in the proper psychosocial development of the child, and must not shy away from educating the child about sexuality (reproductive healthy knowledge).

Also, since positive sexual experiences are associated with general well-being, which generally contribute to public health - emotionally, medically and financially, there is a great need to highlight the importance of sex education in order to promote and increase the sexual health of our future generations (young people).

\section{Acknowledgments:}

We wish to thank the management and teachers of all the participating schools for their effort in the collection of data and their contributions during this process. Also, we are so grateful to all the participants for their cooperation. We are able to understand that money is all things; therefore, we appreciate the research three assistants for their support and understanding.

\section{References}

[1] Adedipe, V. O. (2000). The adolescent problem behaviour (II) Saturday Tribune, October 14th.

[2] Akindele-Oscar, O. B. and Ayodele, K.O. (2004).Undergraduates' knowledge of reproductive health issues and its relationship with their permissive sexual expression.Nigerian Journal of Applied Psychology, 8,1, 240-249.

[3] Ayodele, K.O. (2011). An exploratory study into the sexual behaviour of Nigerian adolescents.Akoka Journal of Education, 5(1), 120-128.

[4] Boone, C., van Olffen, W., \& van Witteloostuijn, A. (2005). Team locus of control composition and leadership structure information and acquisition, and financial performance: A business study simulation. Academy ofManagement Journal, 48(5), 889909.

[5] Ciarrochi, J. V., Chan, A. Y. C. \&Bajgar, J. (2001).Measuring emotional intelligence in adolescents.Personality and Individual Differences, 31, 1105-1119.

[6] Carrim, N. M. H., Basson, J., \& Coetzee, M. (2006).The relationship between job satisfaction and locus of control in a South African call centre environment.South African Journal of Labour Relations, 30(2), 66-81.

[7] Cavazos-Rehg, P. A., Krauss, M. J., Spitznagel, E. L., Schootman, M., Cottler, L. B., \&Bierut, L. J. (2010). Associations between multiple pregnancies and health risk behaviors among U.S. adolescents. Journal of Adolescent Health, 47(6), 600-603.

[8] Davies, S. L., DiClemente, R. J., Wingood, G. M., Harrington, K. F., Crosby, R. A., \&Sionean, C. (2003). Pregnancy desire among disadvantaged African American adolescent females.American Journal of Health Behavior, 27(1), 55-62.

[9] De Graaf, H., Vanwesenbeeck, I., Woertman, L., Keijsers, L., Meijer, S., \&Meeus, W. (2010). Parental support and knowledge and adolescents' sexual health: Testing two mediational models in a national Dutch sample. Journal of Youth and Adolescence, 39(2), 189-198.

[10] Farbstein, J. A. (2011). Does Social Support Impact the Prediction of Locus of Control for University Students Differentiated on Personality and Parenting? A master dissertation.

[11] Fernandez-Berrocal, P. \& Ruiz, D. (2008).Emotional intelligence in education. Electronic Journal of Research in Educational Psychology, 6 (2), 421-436.

[12] Kane, R., \&Wellings, K. (1999). Integrated sexual health services: The views of medical professionals. Culture, Health \& Sexuality, $1(2), 131-145$.

[13] Krivohlavy, J. (2003). Psychologiezdravi (2nd ed.). Praha: Portal.

[14] Landy, F. J., \& Conte, J. M. (2004).Work in the 21st century: An introduction to industrial \& organizational psychology. Boston, MA: McGraw-Hill.

[15] Lee-Kelley, L. (2006). Locus of control and attitudes to working in virtual teams.International Journal of Project Management, 24(3), 234-243.

[16] Littunen, H., \&Storhammar, E. (2000).The indicators of locus of control in the small business context.Journal of Enterprise Culture, 8(4), 343-360. Kuwahara, A., Y. Nishino, T. Ohkubo, I. Tsuji, S. Hisamichi and T. Hosokawa, 2004. Reliability and validity of the multidimensional health locus of control scale in Japan relationship with demographic factors and health related behaviour. Tohoku J. Exp. Med., 203: 37-45.

[17] Mabekoje, S. O. \&Ogunyemi, A. O. (2003). Emotional intelligence within the classroom context: The influence of gender and sociometric status. Journal of Counselling Psychology 9 (1), 94-102

[18] Magnani, R. J., Seiber, E. E., Gutierrez, E. Z., \&Vereau, D. (2001). Correlates of sexual activity and condom use among secondaryschool students in urban peru. Studies in Family Planning, 32(1), 53-66.

[19] Makinde, B.O. (2004). Self-monitoring, physical attractiveness and eating disorders: implication, for females' perception of heterosocial attachment. Nigerian Journal of Applied Psychology, 8, 1, 195-203.

[20] Mann, M., Hosman, C. M. H., Schaalma, H. P., \& de Vries, N. K. (2004).Self-esteem in a broad-spectrum approach for mental health promotion. Health Education Research, 19(4), 357-372. 
[21] Martin, R., Thomas, G., Charles, C., Epitropaki, O., \& McNamara, R. (2005). The role of leader-member exchanges in mediating the relationship between locus of control \& work reactions. Journal of Organisational\& Occupational Psychology, 78, $141-147$.

[22] Mayer, J. D., Caruso, D. R. \&Salovey, P. (2000). Emotional intelligence meets traditional standards for an intelligence. Intelligence, 27, 267-298.

[23] Mayer, J. D., Salovey, P. \& Caruso, D. R. (1999). Mockup draft of 1st edition: test manual for the MSCEIT V.2, multi health system. Unpublished manuscript.

[24] Mayer, J. D., Salovey, P. \& Caruso, D. R. (2002).Mayer Salovey Caruso Emotional Intelligence Test. North Tonawanda, NY: MHS.

[25] Ndu, A. (2000). "The role of the family in managing indiscipline among youths in Nigeria".Journal of Counselling, 1(1), 45 - 51

[26] Nnachi, R. O. (2003). "Causes, consequences and control of behaviour problems among Nigerian children" in Nnachi, R. O. and Ezeh, P. S. E. (Eds.). (2003). The behaviour problems of the Nigerian Child.Awka.The Nigerian Society for Educational Psychologists (NISEP).

[27] Nowicki, S. Jr. \&Schneewind, K. (1982).Relation of family climate variables to locus of control in German and American students. The Journal of Genetic Psychology,141, 277-286.

[28] Odoemelam, A. (1996). "Incidence and management of male and female sexually maladjusted youngsters: genderand counselling implications". The Counsellor.Journal of the Counselling Association of Nigeria. 14 (92), 160-171

[29] Ondrej, K (2012) Sexual risky behaviour among Slovak adolescents and young adults: social and psychological factors. Retrieved from www.findarticle.com on April 6, 2013

[30] Ogunleye, A.J. and Oke, S.O. (2012).Effect of Sexual Self Assertiveness and Sexual Self Esteem on Sexual Self Disclosure among Heterosexual Adolescents in Nigeria.Elixir journal of social sciences, 47, 8817-8820.

[31] Ogunsanya, E.A. (2007). Adolescents' perception of sex symbol, values, risks and misconceptions.Ogun Journal of Counselling Studies, 1, 1, 144-152.

[32] Ogunyemi, A. O. (2008). Measured effects of provocation and emotional mastery techniques in fostering emotional intelligence among Nigerian adolescents.Electronic Journal of Research in Educational Psychology, 6 (2), 281-296

[33] Palmer, B., Donaldson, C., \&Stough, C. (2002).Emotional intelligence and life satisfaction.Personality and Individual Differences, 33, 1091-1100.

[34] Patrick, M. E., \&Maggs, J. L. (2009). Does drinking lead to sex? Daily alcohol-sex behaviors and expectancies among college students.Psychology of Addictive Behaviors, 23(3), 472-481.

[35] Salovey, P., \& Mayer, J. D. (1990).Emotional intelligence.Imagination, Cognition and Personality, 9, 185-211.

[36] Salovey, P., Mayer, J. D., Goldman, S. L., Turvey, C., \&Palfai, T. P. (1995).Emotional attention, clarity, and repair: Exploring emotional intelligence using the Trait Meta-Mood Scale.In J. W. Pennebaker (Ed.), Emotion, disclosure, and health (pp. 125-154). Washington, DC: American Psychological Association.

[37] Saklofske, D. H., Austin, E. J., \&Minski, P. S. (2003). Factor structure and validity of a trait emotional intelligence measure.Personality and Individual Differences, 34, 707-721.

[38] Sieverding, J. A., Adler, N., Witt, S., \& Ellen, J. (2005). The influence of parental monitoring on adolescent sexual initiation.Archives of Pediatrics \& Adolescent Medicine, 159(8), 724-729.

[39] Thayer, J. F., Rossy, L. A., Ruiz-Padial, E., \&Johnsen, B. H. (2003).Gender differences in the relationship between emotional regulation and depressive symptoms.Cognitive Therapy and Research, 27, 349-364.

[40] WHO. (2012). Sexual health Retrieved 5/16/2012, 2012, from http://www.who.int/topics/sexual_health/en/ 